Case Report

\title{
Hemophagocytic Lymphohistiocytosis and Gastrointestinal Bleeding: What a Surgeon Should Know
}

\author{
S. Popeskou, ${ }^{1}$ M. Gavillet, ${ }^{2}$ N. Demartines, ${ }^{3}$ and D. Christoforidis ${ }^{1,4}$ \\ ${ }^{1}$ Department of Surgery, Lugano Regional Hospital, Switzerland \\ ${ }^{2}$ Department of Hematology, University Hospital of Lausanne, Switzerland \\ ${ }^{3}$ Department of Surgery, University Hospital of Lausanne, Switzerland \\ ${ }^{4}$ University Hospital of Lausanne, Switzerland \\ Correspondence should be addressed to S. Popeskou; salvator10@yahoo.com
}

Received 6 April 2015; Accepted 25 May 2015

Academic Editor: Fernando Turégano

Copyright (C) 2015 S. Popeskou et al. This is an open access article distributed under the Creative Commons Attribution License, which permits unrestricted use, distribution, and reproduction in any medium, provided the original work is properly cited.

This paper presents to the surgical community an unusual and often ignored cause of gastrointestinal bleeding. Hemophagocytic syndrome or hemophagocytic lymphohistiocytosis $(\mathrm{HLH})$ is a rare medical entity characterized by phagocytosis of red blood cells, leucocytes, platelets, and their precursors in the bone marrow by activated macrophages. When intestinal bleeding is present, the management is very challenging with extremely high mortality rates. Early diagnosis and treatment seem to be the most important factors for a successful outcome. We present two cases and review another 18 from the literature.

\section{Introduction}

Gastrointestinal (GI) bleeding is a common cause for hospital admission to surgical wards. In westernized countries, the annual incidence of upper GI bleeding is approximately 100 $-200 / 100,000$ and for lower GI bleeding 20-30/100,000. The estimated mortality ranges from $6 \%$ to $10 \%$ for upper GI bleeding and from $2 \%$ to $4 \%$ for lower GI bleeding [1-4]. Most episodes of lower GI bleeding resolve spontaneously, while others can be treated endoscopically or by interventional radiology. A minority of patients become hemodynamically unstable and require emergency surgery. In such cases, the source of bleeding is not always clear and the surgeon may face the difficult decision to perform extensive colonic resections, at a price of significant mortality rates (up to $25 \%$ ), without the certitude of controlling the source of bleeding [5-7]. The most frequent causes of lower GI bleeding are diverticulosis and arterial-venous malformations. Other frequent causes are colitis, neoplasms, inflammatory bowel disease, and hemorrhoids $[8,9]$.

In this paper, we report the dramatic cases of two patients who presented massive lower GI bleeding originating from diffuse GI mucosal ulcerations secondary to acute Epstein
Barr virus (EBV) proliferation and hemophagocytic lymphohistiocytosis (HLH) and review the literature for GI bleeding associated with this rare syndrome.

\section{Case 1}

A 26-year-old male patient, treated for Crohn's disease with azathioprine $(150 \mathrm{mg} / \mathrm{day})$ for 3 years, was admitted to the ENT department of a community hospital for treatment of a febrile pharyngitis with 10-day cefuroxime. Lab tests revealed leucopenia $(2.7 \mathrm{~g} / \mathrm{L}, 89 \%$ neutrophils, $8 \%$ monocytes) and a mild elevation of the liver enzymes. Clinically and radiologically, splenomegaly was present. An active EBV infection (IgG and IgM positive) was diagnosed on hospital day 7 and treatment with valacyclovir ( $1 \mathrm{gr} \times 3 /$ day $)$ was started. At the same day, the patient presented massive lower GI bleeding requiring admission to the ICU. The initial emergency colonoscopy revealed severe pancolitis with multiple ulcerations which was attributed to a flare of Crohn's colitis. Three days later (day 10), despite multiple transfusions, he became hemodynamically unstable due to continuous bleeding $(\mathrm{CRP} 121 \mathrm{mg} / \mathrm{L}$, procalcitonin $1.21 \mathrm{mcg} / \mathrm{L})$. The patient was therefore transferred to our University Hospital. Upon 
arrival, he developed a hypovolemic shock requiring massive blood transfusions and an emergent total colectomy with ileostomy was performed. Broad-spectrum antibiotherapy with piperacillin/tazobactam (4.5 gr $\times 4$ /day) and prednisone $50 \mathrm{mg} / \mathrm{d}$ was initiated in the immediate postoperative period. A thoracic CT-scan showed bilateral pulmonary infiltrates, which were attributed to transfusion related acute lung injury (TRALI). Blood tests revealed pancytopenia and increasing levels of ferritin $(2600 \mathrm{mg} / \mathrm{L})$ thought to be due to the combination of inflammation and azathioprine treatment. Three days later (day 13), the patient was transferred back to the ICU of the first hospital.

There, severe mononucleosis with persistent high EBV viremia despite antiviral treatment was diagnosed. The patient presented multiple episodes of upper GI bleeding that required further repeated transfusions. Upper endoscopy revealed hemorrhagic gastroduodenitis with multiple bleeding ulcers. Blood tests revealed a further increase of ferritin (up to $15,000 \mu \mathrm{g} / \mathrm{L}$ ) and $\mathrm{LDH}$ (up to $4000 \mathrm{U} / \mathrm{L}$ ) together with worsening pancytopenia and finally agranulocytosis. Repeated bone morrow biopsies finally revealed HLH with macrophage activation syndrome and hemophagocytosis. The patient was treated with high doses of steroids alone and exhibited transient improvement but eventually expired following multiple organ failure 12 days later. The biopsies from gastric, duodenal, and colonic tissues all revealed an EBVassociated lymphoid proliferation. The autopsy concluded to a generalized EBV infection with lymphoid proliferation of the entire digestive tube and multiple organs, with associated secondary macrophage activation syndrome.

\section{Case 2}

A 61-year-old male patient in good general health presented with an episode of significant lower GI bleeding. The patient had had a minor similar episode 4 months ago. One month ago, he had felt fatigue and repeated episodes of fever without any other specific symptoms.

Upon primary admission to another hospital, the patient was tachycardic and slightly hypotensive but improved after massive hydration and was transferred to our center. An upper endoscopy revealed only a small Mallory-Weiss type ulcer, which seemed unlikely to have been the source of bleeding. An angio-CT-scan of the abdomen revealed extensive diverticulosis with signs of transverse colitis but without a precise source of bleeding. The patient was treated conservatively but, in the following days, he developed fever and an important inflammatory syndrome (CRP $253 \mathrm{mg} / \mathrm{L}$, normal leucocyte count) with rhabdomyolysis, acute renal failure, and high levels of LDH (1451 U/L) and ferritin $(1200 \mathrm{mg} / \mathrm{L})$ along with anemia and progressive thrombocytopenia. Three days after his admission, he once again became hemodynamically unstable due to recurrent massive low GI bleeding. From the time of patient's entry to that point, he had received a total of 10 units of RBC. Emergency laparotomy with intraoperative colonoscopy and enteroscopy was performed. Findings were an important inflammatory status around the transverse colon, a small intestinal perforation at the distal ileum, and 10-20 ulcerated inflammatory lesions in the ileum, one of which was actively bleeding. A resection of $60 \mathrm{~cm}$ of ileum was carried out and the patient was admitted to the ICU for postoperative surveillance. Histopathology of the ileum revealed a high grade NK-T lymphoma Epstein Barr virus (EBV) positive.

Two days after surgery, the patient became septic. A thoracoabdominal CT-scan showed bilateral pleural effusions but no specific septic source. In the absence of radiological signs that would explain the patient's septic status, a "second look" laparotomy was performed but no source of sepsis was identified. Subsequently, the patient's condition deteriorated rapidly. He developed disseminated intravascular coagulation and finally a new episode of GI bleeding. Based on the above listed observations together with ferritin levels at $15000 \mathrm{mcg} / \mathrm{L}, \mathrm{HLH}$ was suspected and a treatment with CHOP regimen (cyclophosphamide $750 \mathrm{mg} / \mathrm{m}^{2}$ day 1, doxorubicin $50 \mathrm{mg} / \mathrm{m}^{2} /$ day 1 , Oncovin $1.4 \mathrm{mg} / \mathrm{m}^{2} /$ day 1 , and prednisone $60 \mathrm{mg} / \mathrm{m}^{2} /$ day 1 to 5) plus etoposide was initiated. No bone marrow biopsies were performed as death due to hemodynamic instability followed the next day. Autopsy revealed a NK-T extranasal EBV + lymphoma with intestinal localization. Bone marrow presented with massive hemophagocytosis without any evidence of tumor infiltration (see Figure 1).

\section{Discussion}

Hemophagocytic lymphohistiocytosis (HLH) or hemophagocytic syndrome represents a rare pathophysiologic entity characterized by a hyperinflammatory state, cytokine deregulation, impaired function of cytotoxic T-cells (CTL), and natural killer (NK) cells in addition to hemophagocytosis (i.e., phagocytosis by activated macrophages of red blood cells, leucocytes, platelets and their precursors in the blood marrow, spleen, or other lymphoid organs) [23, 24].

There is an inherited or familial form (FHLH) and an acquired or secondary HLH [25]. The FHLH incidence is estimated to be $0.12 / 100.000$ children per year and has its onset under the age of 1 year in the majority $(70 \%-80 \%)$ of patients [26]. Patients with inherited immune deficiencies like the Chediak-Higashi syndrome as well as the X-linked proliferative syndrome are also at high risk to develop HLH.

Secondary HLH may occur at all ages [24] and is usually diagnosed in association with malignant (mostly with cutaneous or anaplastic lymphomas), autoimmune, or infectious diseases. Infection associated with HLH is mostly associated with viral infections of the herpes group, in particular EBV and cytomegalovirus (CMV) [23, 25]. EBV induced HLH may mimic or favor T-cell lymphoma and other EBV-linked lymphoproliferative disorders [23]. Other nonviral agents such as bacteria, mycobacteria, protozoa, and fungi can more rarely trigger HLH [24]. Cases of HLH after immunization with measles vaccine, probably in predisposed patients, have also been documented [27].

The dominant clinical characteristics of HLH are persistent fever, usually unresponsive to antibiotics, splenomegaly and/or hepatomegaly, lymphadenopathies, icterus, rash, anorexia, and GI bleeding. Neurological symptoms, such as 


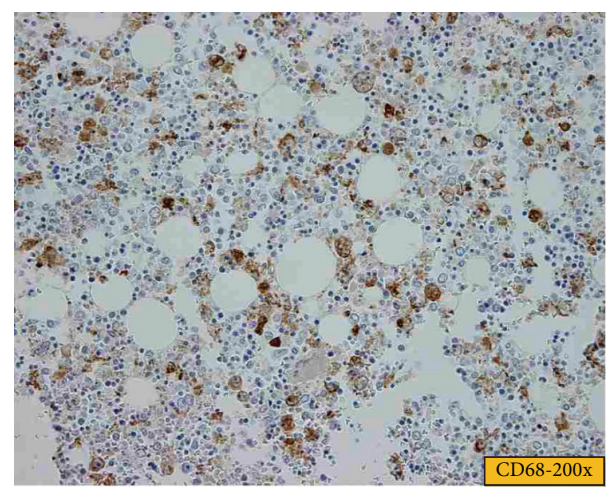

Figure 1: Hemophagocytosis in the bone marrow of Case 2.

seizures or cranial nerve palsies, are rare in the acquired form but are found in up to 1/3 of patients with FHLH [25, 28-30].

Laboratory findings include cytopenia, in at least two cell lineages, elevated hemolysis parameters, hypofibrinogenemia (and possibly disseminated intravascular coagulation), hypertriglyceridemia, and hyperferritinemia. Inflammatory markers like the C-reactive protein may be quite high due to the syndrome's inflammatory state. Special markers include increased soluble CD25 (alpha-chain of the interleukin (IL-2) receptor) reflecting increased $\mathrm{T}$ lymphocytes activation and turnover and profoundly decreased or absent NK cell activity $[24,29,31]$. The Th1/Th2 biomarker is another recently developed diagnostic tool [32].

Diagnosis in patients with clinical suspicion of $\mathrm{HLH}$ requires bone marrow aspiration and biopsy. Positive biopsies reveal normal maturation of all cell lineages, normal or increased cellularity, and infiltration with macrophages/ histiocytes associated with hemophagocytosis [25]. However, hemophagocytosis is often initially absent, requiring a repeated exam [24]. Due to the insidious nature of HLH, diagnosis is difficult, needs to be based on a combination of clinical and biological criteria, and is frequently established after the patient's death $[22,25,33]$.

Infections must be actively sought as they may be the trigger of the syndrome and represent a treatable cause. Patients should be tested for EBV, CMV, herpes simplex, and adenovirus [24]. Screening for less frequent infectious agents, inherited immune deficiencies, and underlying malignancies should be done according to clinical suspicion.

$\mathrm{HLH}$, whether acquired or familial, is a severe condition and, if left untreated, can lead to rapid deterioration and death. There is no high level evidence to guide treatment; the most widely accepted strategy is aggressive systemic therapy with various combinations of immunosuppressive and chemotherapeutic agents, along with the treatment of the underlying causes, if identified. For the severe forms of the FHLH, hematopoietic stem cell transplantation is currently considered to be the only curative option [32]. FHLH therapies with antithymocyte globulin, steroids, cyclosporin $\mathrm{A}$, and intrathecal methotrexate to pediatric patients have been reported with $73 \%$ rapid and complete response [30]. Due to the lack of studies in the adult population, patients are usually treated with a regimen adapted from pediatric protocols [29]. For adult patients with HLH secondary to pathogens other than EBV, supportive care and treatment of the underlying infection are associated with recovery in $60 \%-$ $70 \%$ [34]. EBV-associated HLH is almost universally fatal if untreated, with death resulting usually from multiorgan failure $[31,35]$.

The goal of this paper is to raise awareness among surgeons about the rare medical entity of HLH, which may present as a highly life threatening form of GI bleeding. In both cases presented in this paper, the surgeon was faced with a clinical picture of severe GI bleeding. These patients had presented a series of systemic clinical and laboratory findings compatible with HLH (fever unresponsive to antibiotics, splenomegaly, EBV infection, cytopenia, and high ferritin levels) earlier in the course of their illness, but diagnosis of HLH was not suspected until late. Surgical therapy for the GI bleeding was challenging in both cases as the bleeding source had not been localized precisely preoperatively. In the first patient, total colectomy was performed, but bleeding recurred, possibly from the documented coexisting gastroduodenal ulcerations. In the second patient, intraoperative colonoscopy and enteroscopy helped localize the source and guide the extent of the resection, but bleeding recurred as well. The role of surgery cannot be denied in the acute setting of life threatening GI bleeding. However, in these cases, earlier diagnosis and medical treatment of HLH might have prevented fatal recurrence.

The true incidence of GI bleeding in association with $\mathrm{HLH}$ is hard to estimate. Guo et al., in a retrospective analysis of 41 children with HLH, reported a rate of $12.2 \%$ [36]. In our review of the literature on HLH with associated GI bleeding, we found only a few other case reports (Table 1). Similar to our two cases, mortality was very high (12 deaths out of 18) and almost always secondary to uncontrollable GI bleeding. Of course, the severity of bleeding in this small review may be overrated due to selection and publication bias. The origin of bleeding can be localized throughout the GI tract. Our two patients bled form the colon, the small bowel, and the stomach. The bleeding source can be diffuse or from linear isolated ulcers. These gastrointestinal lesions are secondary to transmural lymphohistiocytic infiltration of macrophages as reported in histological findings [22], which in addition to bleeding may lead to perforation, as in one of our patients. Septic complications may be masked from the underlying hyperinflammatory state caused by HLH. Emergent surgery for intestinal resections or embolization was part of successful treatment in some reports $[15,20,36]$; in others, similar to our patients, it did not help control bleeding definitively [11, 19, 20, 22]. Administration of recombinant activated factor VII seemed to provide short temporary but no definitive control of bleeding in some reports $[22,37]$.

Hemophagocytic lymphohistiocytosis (HLH) is an elusive medical entity, difficult to diagnose. It may be present as life threatening GI bleeding and pose a challenging clinical problem to the surgeon. Associated cytopenia, high ferritin, and low fibrinogen levels, in combination with symptoms and signs such as fever, hepatosplenomegaly, skin rash, and lymphadenopathies, should raise suspicion early. Viral (EBV, 


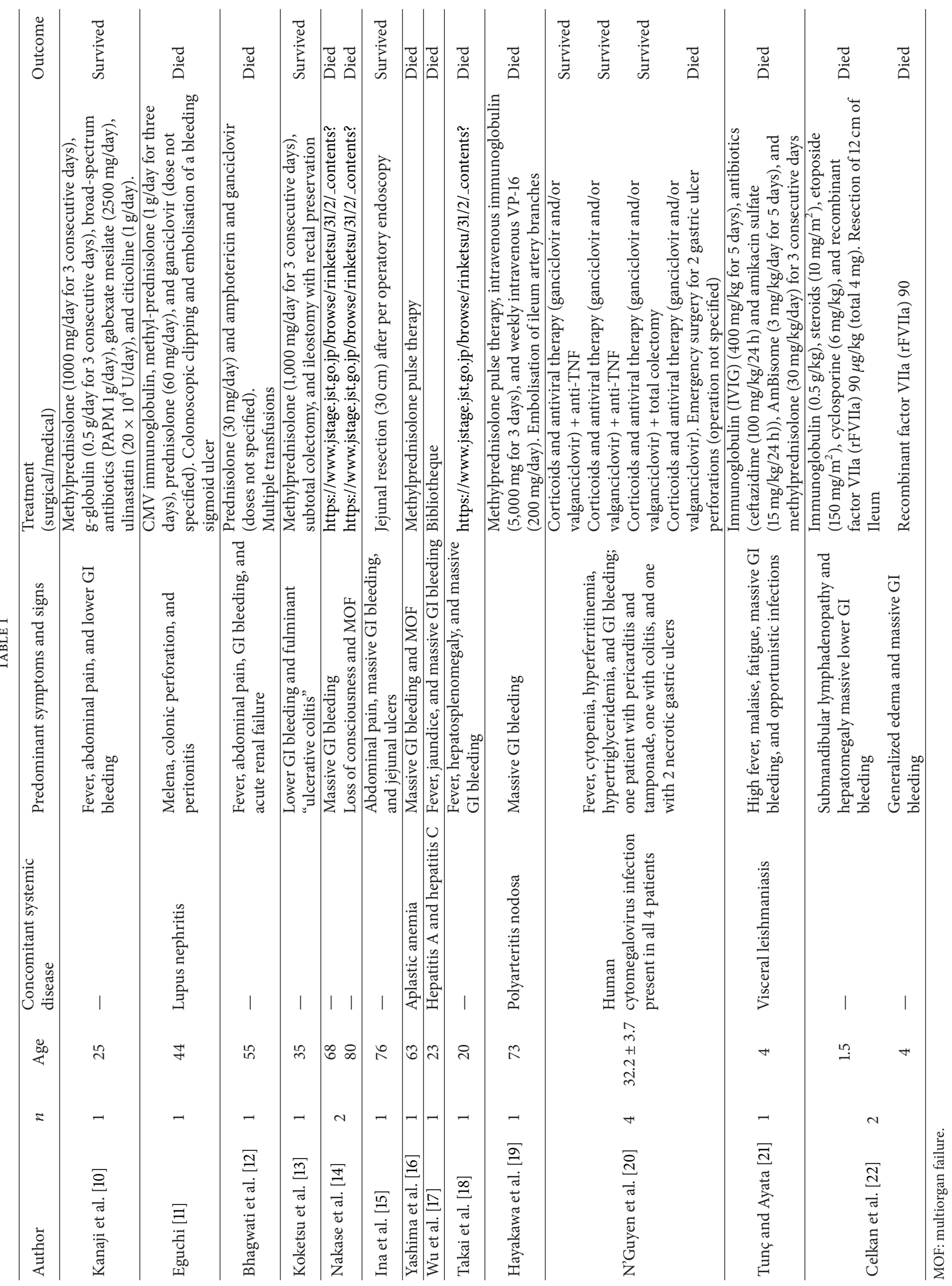


CMV, and herpes simplex virus) and other (Mycobacterium tuberculosis and Mycoplasma pneumonia) infections should be looked for as they may represent treatable causes. Treatment requires a multidisciplinary approach and surgery may provide a temporary solution for GI bleeding or perforation, but early diagnosis and systemic therapy are the only hope for cure.

\section{Conflict of Interests}

The authors declare that there is no conflict of interests regarding the publication of this paper.

\section{References}

[1] C. M. Wilcox, B. L. Cryer, H. J. Henk et al., "Mortality associated with gastrointestinal bleeding events: comparing short-term clinical outcomes of patients hospitalized for upper GI bleeding and acute myocardial infarction in a US managed care setting," Clinical and Experimental Gastroenterology, vol. 2, pp. 21-30, 2009.

[2] G. F. Longstreth, "Epidemiology of hospitalization for acute upper gastrointestinal hemorrhage: a population-based study," The American Journal of Gastroenterology, vol. 90, no. 2, pp. 206-210, 1995.

[3] R. T. Yavorski, R. K. H. Wong, C. Maydonovitch, L. S. Battin, A. Furnia, and D. E. Amundson, "Analysis of 3,294 cases of upper gastrointestinal bleeding in military medical facilities," The American Journal of Gastroenterology, vol. 90, no. 4, pp. 568-573, 1995.

[4] D. R. Parker, X. Luo, J. J. Jalbert, and A. R. Assaf, "Impact of upper and lower gastrointestinal blood loss on healthcare utilization and costs: a systematic review," Journal of Medical Economics, vol. 14, no. 3, pp. 279-287, 2011.

[5] W. Browder, E. J. Cerise, and M. S. Litwin, "Impact of emergency angiography in massive lower gastrointestinal bleeding," Annals of Surgery, vol. 204, no. 5, pp. 530-536, 1986.

[6] I. M. Leitman, D. E. Paull, and G. T. Shires III, "Evaluation and management of massive lower gastrointestinal hemorrhage," Annals of Surgery, vol. 209, no. 2, pp. 175-180, 1989.

[7] J. Lee, T. W. Costantini, and R. Coimbra, "Acute lower GI bleeding for the acute care surgeon: current diagnosis and management," Scandinavian Journal of Surgery, vol. 98, no. 3, pp. 135-142, 2009.

[8] C. Gayer, A. Chino, C. Lucas et al., "Acute lower gastrointestinal bleeding in 1,112 patients admitted to an urban emergency medical center," Surgery, vol. 146, no. 4, pp. 600-607, 2009.

[9] A. M. Vernava III, W. E. Longo, K. S. Virgo, and F. E. Johnson, "A nationwide study of the incidence and etiology of lower gastrointestinal bleeding," Surgical Research Communications, vol. 18, no. 2, pp. 113-120, 1996.

[10] S. Kanaji, K. Okuma, Y. Tokumitsu, S. Yoshizawa, M. Nakamura, and Y. Niho, "Hemophagocytic syndrome associated with fulminant ulcerative colitis and presumed acute pancreatitis," The American Journal of Gastroenterology, vol. 93, no. 10, pp. 1956-1959, 1998.

[11] K. Eguchi, "Systemic lupus erythematosus complicated by cytomegalovirus-induced hemophagocytic syndrome and colitis," Internal Medicine, vol. 41, no. 2, pp. 77-78, 2002.
[12] N. S. Bhagwati, S. J. Oiseth, L. S. Abebe, and P. H. Wiernik, "Intravascular lymphoma associated with hemophagocytic syndrome: a rare but aggressive clinical entity," Annals of Hematology, vol. 83, no. 4, pp. 247-250, 2004.

[13] S.-I. Koketsu, T. Watanabe, N. Hori, N. Umetani, Y. Takazawa, and H. Nagawa, "Hemophagocytic syndrome caused by fulminant ulcerative colitis and cytomegalovirus infection: report of a case," Diseases of the Colon \& Rectum, vol. 47, no. 7, pp. 12501253, 2004.

[14] T. Nakase, K. Morita, M. Tomeoku, and M. Katou, "Hemophagocytic syndrome in two elderly men," Rinsho Ketsueki, vol. 31, no. 2, pp. 258-259, 1990.

[15] S. Ina, M. Tani, K. Takifuji, S. Yamazoe, Y. Nakatani, and H. Yamaue, "Virus-associated hemophagocytic syndrome and hemorrhagic jejunal ulcer caused by cytomegalovirus infection in a non-compromised host; a case report of unusual entity," Hepato-Gastroenterology, vol. 51, no. 56, pp. 491-493, 2004.

[16] A. Yashima, Y. Narigasawa, Y. Ishida et al., "Hemophagocytic syndrome due to miliary tuberculosis in the course of aplastic anemia," Rinsho Ketsueki, vol. 39, no. 5, pp. 392-397, 1998.

[17] C.-S. Wu, K.-Y. Chang, P. Dunn, and T.-H. Lo, "Acute hepatitis A with coexistent hepatitis $C$ virus infection presenting as a virusassociated hemophagocytic syndrome: a case report," American Journal of Gastroenterology, vol. 90, no. 6, pp. 1002-1005, 1995.

[18] K. Takai, M. Sanada, and H. Shibuya, "Epstein-Barr virus associated natural killer cell leukemia: report of an autopsy case," Rinsho Ketsueki, vol. 36, no. 5, pp. 500-505, 1995.

[19] I. Hayakawa, F. Shirasaki, H. Ikeda et al., "Reactive hemophagocytic syndrome in a patient with polyarteritis nodosa associated with Epstein-Barr virus reactivation," Rheumatology International, vol. 26, no. 6, pp. 573-576, 2006.

[20] Y. N'Guyen, S. Baumard, J. H. Salmon et al., "Cytomegalovirus associated hemophagocytic lymphohistiocytosis in patients suffering from crohn's disease treated by azathioprine: a series of four cases," Inflammatory Bowel Diseases, vol. 17, no. 9, pp. E116E118, 2011.

[21] B. Tunç and A. Ayata, "Hemophagocytic syndrome: a rare lifethreatening complication of visceral leishmaniasis in a young boy," Pediatric Hematology and Oncology, vol. 18, no. 8, pp. 531536, 2001.

[22] T. Celkan, S. Alhaj, M. Civilibal, and M. Elicevik, "Control of bleeding associated with hemophagocytic syndrome in children: an audit of the clinical use of recombinant activated factor VII," Pediatric Hematology and Oncology, vol. 24, no. 2, pp. 117121, 2007.

[23] D. N. Fisman, "Hemophagocytic syndromes and infection," Emerging Infectious Diseases, vol. 6, no. 6, pp. 601-608, 2000.

[24] G. E. Janka, "Hemophagocytic syndromes," Blood Reviews, vol. 21, no. 5, pp. 245-253, 2007.

[25] R. J. Arceci, "When T cells and macrophages do not talk: the hemophagocytic syndromes," Current Opinion in Hematology, vol. 15, no. 4, pp. 359-367, 2008.

[26] J.-I. Henter, G. Elinder, O. Soder, and A. Ost, "Incidence in Sweden and clinical features of familial hemophagocytic lymphohistiocytosis," Acta Paediatrica, vol. 80, no. 4, pp. 428435, 1991.

[27] T. Otagiri, T. Mitsui, T. Kawakami et al., "Haemophagocytic lymphohistiocytosis following measles vaccination," European Journal of Pediatrics, vol. 161, no. 9, pp. 494-496, 2002. 
[28] J. I. Henter, M. Aricò, G. Elinder, S. Imashuku, and G. Janka, "FHLH. Primary hemophagocytic lymphohistiocytosis," Hematology/Oncology Clinics of North America, vol. 12, no. 2, pp. 417433, 1998.

[29] J.-I. Henter, A. Horne, M. Aricó et al., "HLH-2004: diagnostic and therapeutic guidelines for hemophagocytic lymphohistiocytosis," Pediatric Blood and Cancer, vol. 48, no. 2, pp. 124-131, 2007.

[30] N. Mahlaoui, M. Ouachée-Chardin, G. D. S. Basile et al., "Immunotherapy of familial hemophagocytic lymphohistiocytosis with antithymocyte globulins: a single-center retrospective report of 38 patients," Pediatrics, vol. 120, no. 3, pp. e622-e628, 2007.

[31] J. Chen, G. Li, J. Lu et al., "A novel type of PTD, common helixloop-helix motif, could efficiently mediate protein transduction into mammalian cells," Biochemical and Biophysical Research Communications, vol. 347, no. 4, pp. 931-940, 2006.

[32] Y.-M. Tang and X.-J. Xu, "Advances in hemophagocytic lymphohistiocytosis: pathogenesis, early diagnosis/differential diagnosis, and treatment," The Scientific World Journal, vol. 11, pp. 697708, 2011.

[33] G. E. Janka, "Familial and acquired hemophagocytic lymphohistiocytosis," European Journal of Pediatrics, vol. 166, no. 2, pp. 95-109, 2007.

[34] A. P. Reiner and J. L. Spivak, "Hematophagic histiocytosis. A report of 23 new patients and a review of the literature," Medicine, vol. 67, no. 6, pp. 369-388, 1988.

[35] C. Cerboni, A. Zingoni, M. Cippitelli, M. Piccoli, L. Frati, and A. Santoni, "Antigen-activated human T lymphocytes express cellsurface NKG2D ligands via an ATM/ATR-dependent mechanism and become susceptible to autologous NK-cell lysis," Blood, vol. 110, no. 2, pp. 606-615, 2007.

[36] X. Guo, Q. Li, and C.-Y. Zhou, "Retrospective analysis of 41 childhood hemophagocytic syndrome," Zhonghua Xue Ye Xue Za Zhi, vol. 28, no. 7, pp. 449-453, 2007.

[37] C. G. Millar, M. D. Stringer, I. Sugarman, and M. Richards, "The use of recombinant factor VIIa for bleeding in paediatric practice," Haemophilia, vol. 11, no. 2, pp. 171-174, 2005. 


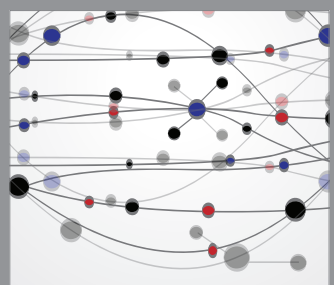

The Scientific World Journal
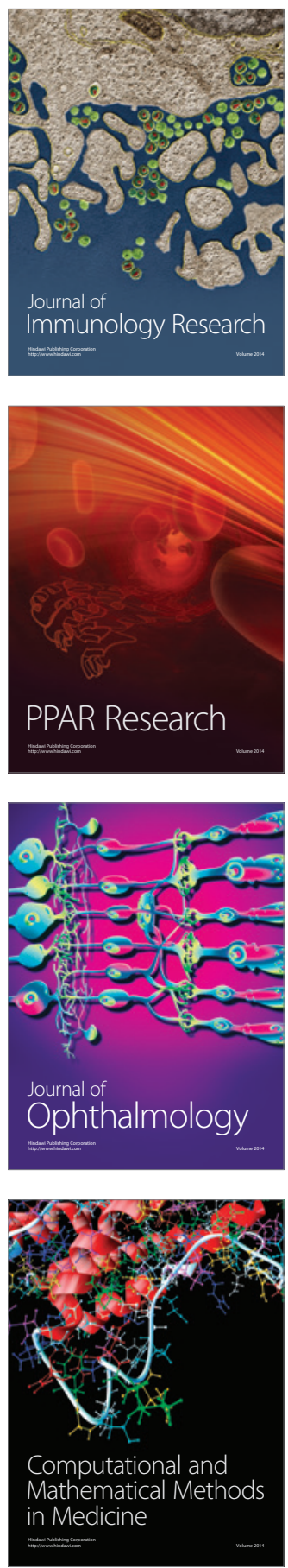

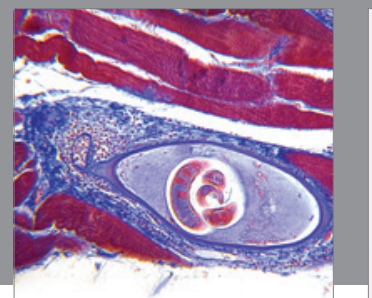

Gastroenterology

Research and Practice
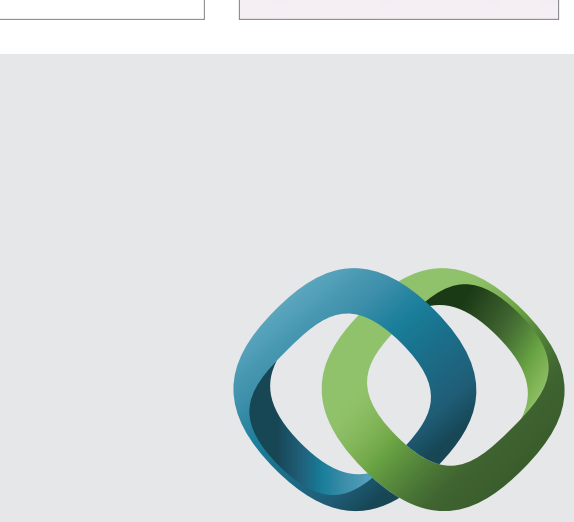

\section{Hindawi}

Submit your manuscripts at

http://www.hindawi.com
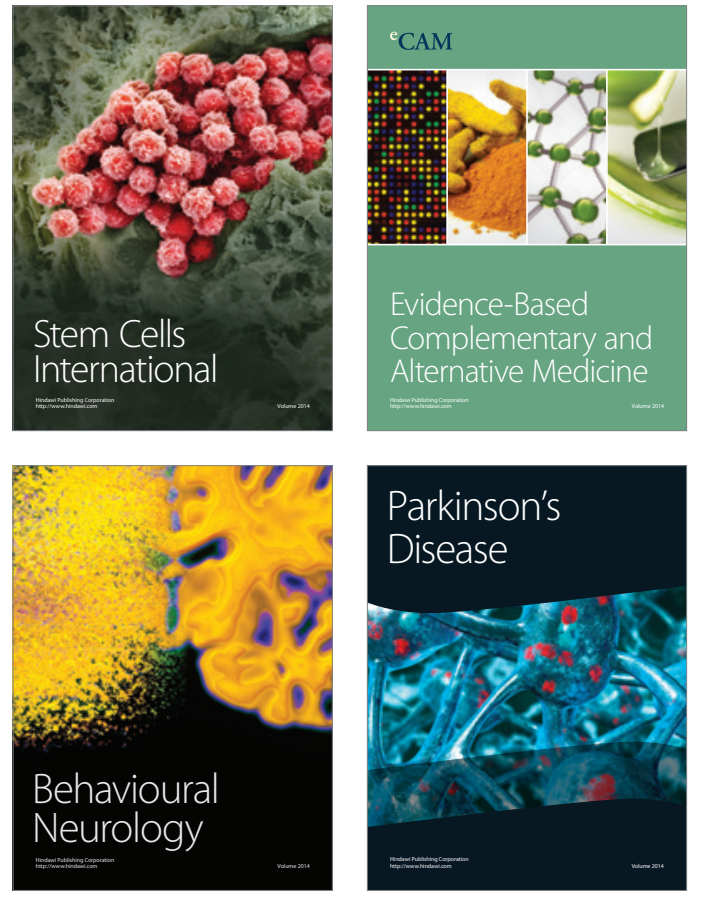
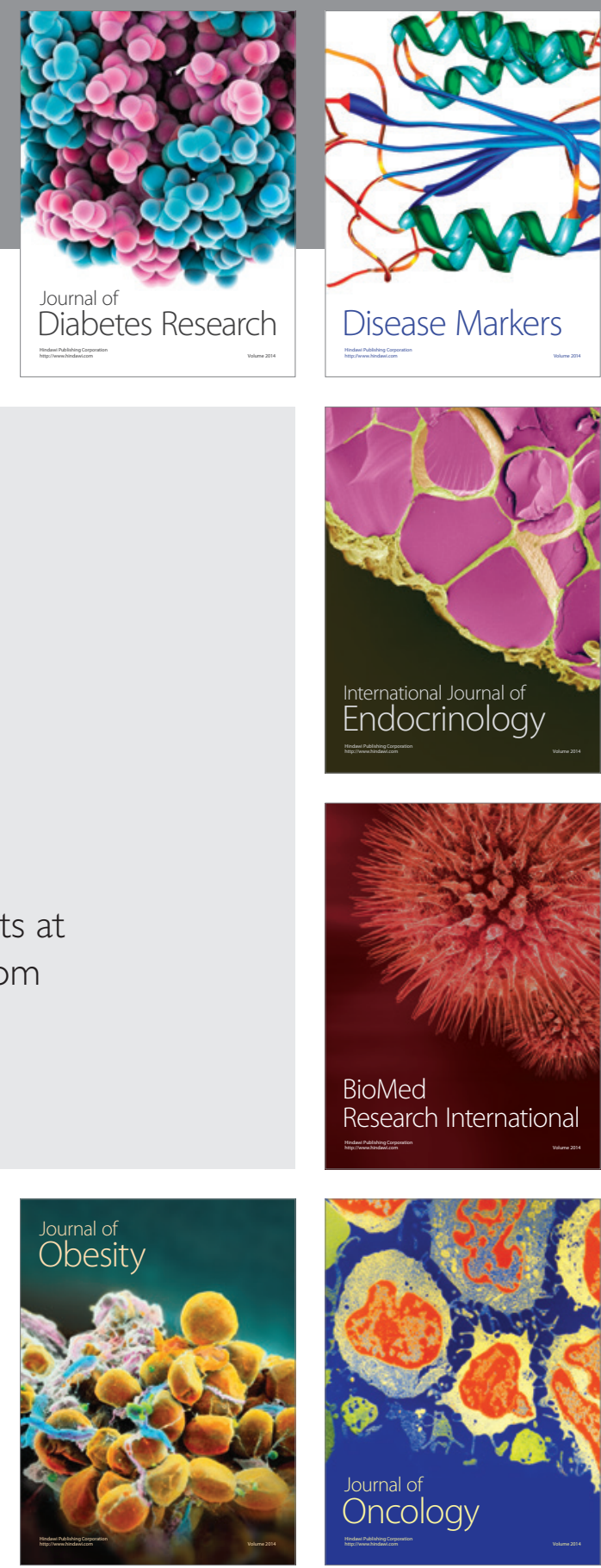

Disease Markers
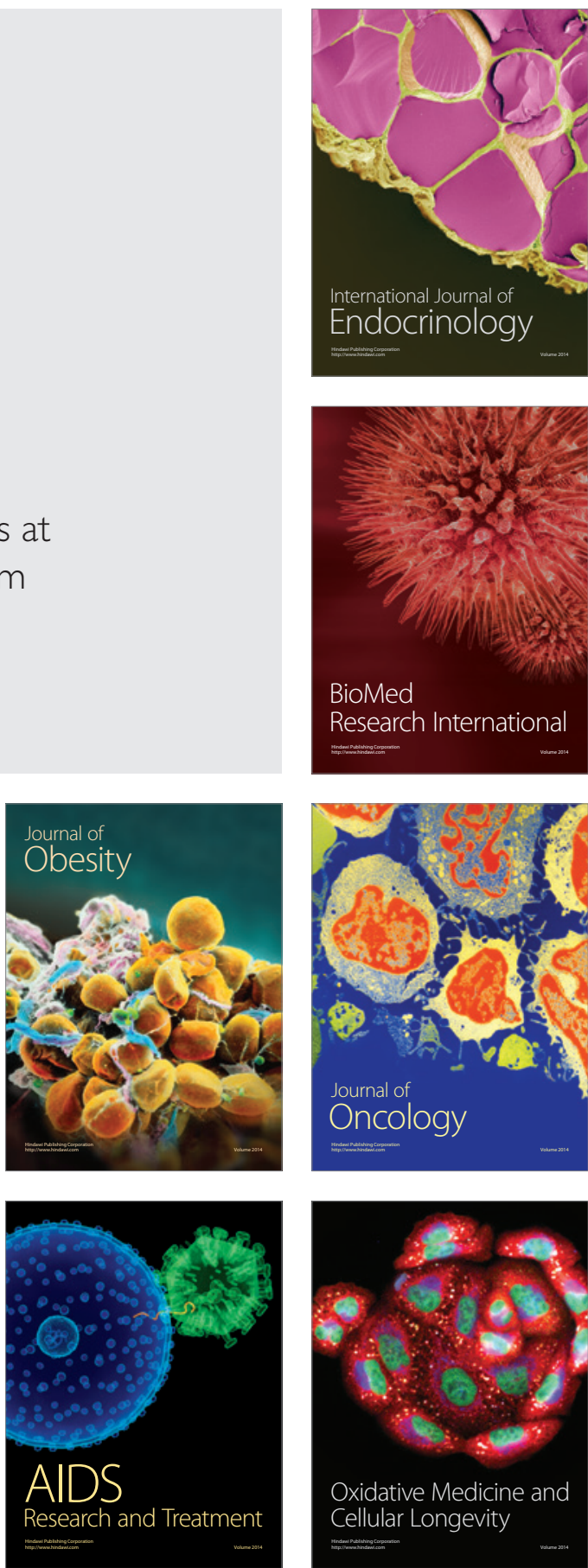